
FUNDAMENTOS, TEORIAS E ASPECTOS METODOLÓGICOS DISCIPLINARES APLICADOS NA BIÔNICA E BIOMIMÉTICA 


\section{SOBRE OS AUTORES}

Georgia Victor I georgiaribeirovictor@gmail.com

Lattes: http://buscatextual.cnpq.br/buscatextual/visualizacv.do?id=K4727073A1

Coordenadora do Grupo de Estudos em BioTensegrity - MEDPUC e Laboratório de Investigação em Livre Desenho LILD/DAD/PUC-Rio. Pesquisa e desenvolve modelos dinâmicos do corpo humano, para aplicação em aulas de anatomia ativa. Designer - UFPB. Formação em Terapia Corporal (não acadêmica). Especialização em Ergonomia GENTE/COPPE/UFRJ. Mestre em Engenharia de Produção e do Produto/Saúde no trabalho/COPPE/UFRJ. Doutora em Design. Tese: Design para Saúde. LILD/ DAD/ PUC-Rio. Especialização em Docência em Medicina e Ciências das Saúde, MEDPUC - PUC-Rio.

Linha de pesquisa: Biodesign- Biomimética - Biotensegrity - Cadeias Mio-fasciais.

Mario Seixas I mario@bambutec.com.br

Lattes: http://buscatextual.cnpq.br/buscatextual/visualizacv.do?id=K4766742P7

CV: Diretor da empresa Bambutec Design. Professor do Departamento de Artes \& Design da PUC-Rio. Pesquisador do Laboratório de Investigação em Livre Desenho LILD - DAD/ PUC-Rio e do Grupo de Materiais e Tecnologias Não Convencionais GMTENC - Departamento de Engenharia Civil e Ambiental/PUC-Rio. Desenhista Industrial PUC-Rio. Mestre em Design. Dissertação: Inserção social de arquiteturas temporárias de bambus e lonas têxteis utilizando tecnologias não convencionais. LILD/ DAD/ PUC-Rio.

Linha de pesquisa: Objetos de bambu- Tensoestruturas - Fibras naturais - Tensegrity- Biotensegrity - Estruturas autoportantes - Bambu na construção civil.

José Luís Mendes Ripper I ripper@puc-rio.br

Lattes: http://buscatextual.cnpq.br/buscatextual/visualizacv.do?id=K4783810J9

Professor emérito da PUC-Rio. Coordenador do Laboratório de Investigação em Livre. Desenho LILD DAD/ PUC-Rio. Arquiteto - UFRJ. Livre Docente - PUC-Rio.

Linha de pesquisa: Objetos de bambu - Biomimética - Tensegrity - Biotensegrity - Tensoestruturas - Estruturas autoportantes - Bambu na construção civil - Biodesign - Fibras naturais. 


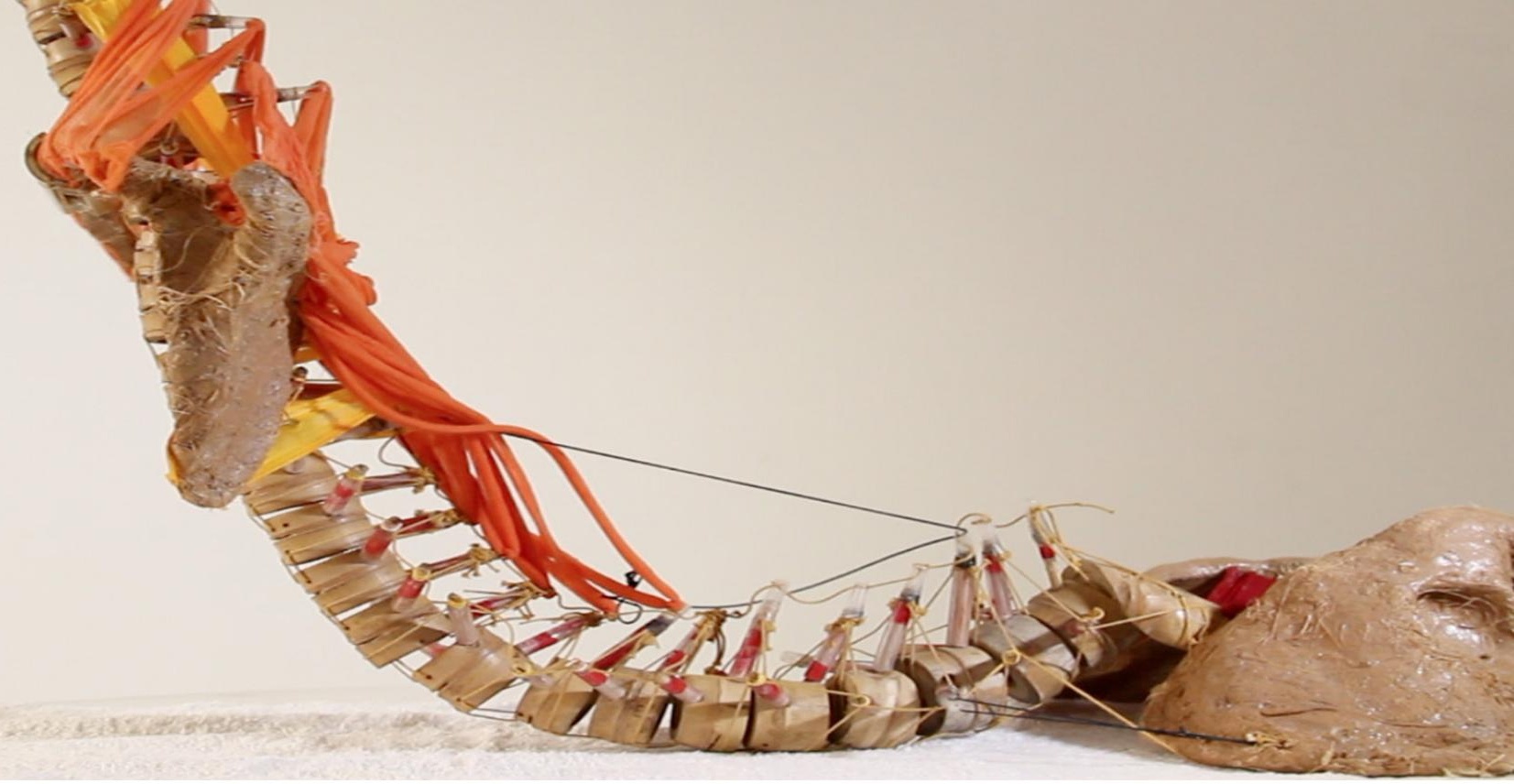

\title{
Estruturas Autoportantes Biotensegrity Aplicando Materiais Naturais
}

\author{
Biotensegrity Self-supporting Structures Applying \\ Bio-based Materials
}

\author{
Georgia Victor I Mario Seixas I José Luís Mendes Ripper
}

\section{Resumo}

O presente trabalho apresenta resultados de pesquisa em estruturas autoportantes empregando o sistema estrutural de tensão integral (tensegrity) aplicado nas áreas do design, arquitetura, engenharia e medicina. Metodologias ativas de pesquisa e aprendizagem foram desenvolvidas utilizando modelos experimentais no meio físico e social. Recentes avanços nas pesquisas em estruturas tensegrity orientaram o desenvolvimento de protótipos que introduzem o sistema biotensegrity na arquitetura sustentável e no desenho de modelos didáticos do corpo humano. Os modelos desenvolvidos através de estudos em biomimética aplicam tecnologias têxteis e ligações flexíveis em biomateriais, apropriados ao ambiente e capazes de absorver esforços e cargas especiais, que se assemelham à constituição fisiológica dos animais vertebrados e do corpo humano.

Palavras-chave: Estruturas autoportantes; Tensegrity; Biotensegrity; Biomateriais; Estruturas de membrana; Biomimética.

\begin{abstract}
The present paper present research results in self-supporting structures employing the tensional integrity structural system applied in the design, architecture, engineering and medicine. Active methods of research and learning developed using experimental models in physical and social environments. Recent advances in research on tensegrity structures have guided the development of prototypes that introduce the biotensegrity system into sustainable architecture and in the design of didactic models of the human body. The models developed through studies in biomimetics apply textile-based technologies and flexible connections in biomaterials, environmentally compatible and capable of absorbing forces and special loadings, which are similar to the physiological constitution of vertebrate animals and the human body.
\end{abstract}

Keywords: Self-supporting structures; Tensegrity; Biotensegrity; Bio-based materials; Membrane structures; Biomimetics. 


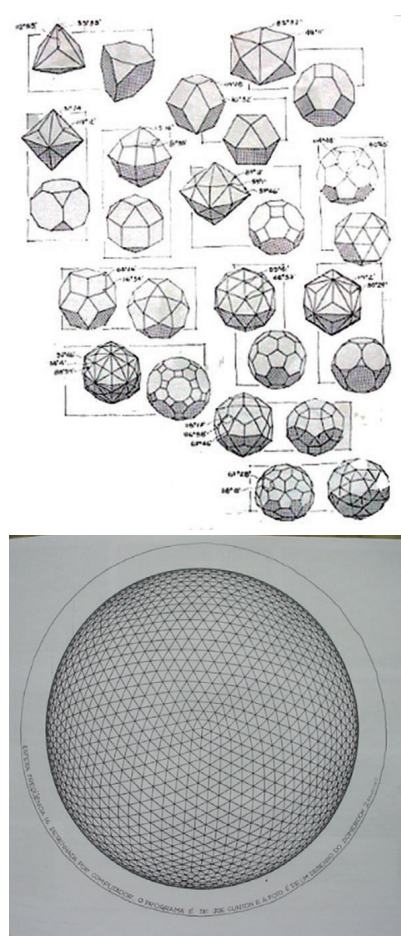

Figura 1: Geometrias geodésicas a partir retículas triangulares

Fonte: Lotufo e Lopes, 1981.

"Uma estrutura fractal é uma estrutura cuja resolução permanece coerente em diferentes graus ou níveis de observação. Em outras palavras, ela é construída com desenhos repetitivos que se reorganizam em diferentes níveis para produzir uma forma que conserva uma estrutura de base análoga. Assim acontece com um feto, um cristal, uma encosta rochosa vista de avião ou observada em escala humana. As formações dos cristais de rocha e de gelo, a estrela do mar, a rosa, a petúnia, o jasmimestrela, a teia de aranha, os rabos dos cavalos marinhos, os furacões, as asas de borboleta, a foz de rios, as cadeias de montanhas ou os relâmpagos, como também a constituição do corpo humano, são exemplos apresentados para representar a natureza fractal das formas naturais" (Rosnay, 1997).

\section{INTRODUÇÃO}

A sustentação da vida se realiza a partir de uma profunda relação entre forças, formas e energias. Durante milhões de anos, a vida vem desenvolvendo e aprimorando estruturas e organizações da matéria, de micro a macro sistemas complexos em coexistência, sistemas vivos que constituem a vida no planeta Terra. Esses sistemas vivos se auto-organizam e influenciam uns aos outros em um conjunto de inter-relações que configuram unidades de unidades em interação dinâmica. A Física emprega a palavra interação para se referir a ações recíprocas entre elementos que cooperam e, por isso, se transformam, modificando seu comportamento interno e sua natureza externa (Capra, 2002).

A natureza é capaz de produzir sofisticadas formas interdependentes de vida e sistemas informacionais em redes eletromagnéticos, a partir de dispositivos de atração e repulsão. Uma característica comum a todos os sistemas vivos é a economia de energia para um máximo de performance, pois observamos que na natureza não há desperdício de energia para o desempenho das funções essenciais aos sistemas vivos (Otto, 1998). O funcionamento de um sistema vivo exige comunicação entre as partes que o constituem. As partes de um sistema interagem e se solidarizam mantendo uma unidade, uma organização dinâmica que configura organismos autônomos, de células a planetas. Esta forma de estruturação cooperativa permite a sustentabilidade do sistema vivo em um nível de átomos mas também na escala da comunidade humana, na escala planetária e também na escala cósmica. No funcionamento de um sistema vivo, o comportamento das partes é refletido no funcionamento do "todo", que por sua vez, irá apresentar propriedades novas, inexistentes em suas partes. Concordamos com Milton Santos, que a diversificação da natureza se configura em padrões dinâmicos, onde o movimento é essencial à vida. A humanidade acrescenta o dado social da produção aos processos biológicos, complexificando as interações presentes nos sistemas vivos (Santos, 2002).

As formas produzidas pela natureza nos levam a perceber organizações nos processos de formação da matéria formando redes micro e macrocósmicas, estruturas solidárias e resilientes. Sua organização pode ser percebida através de retículas de triângulos, originando complexas organizações espaciais geodésicas, entre os quais podemos observar tetraedros, octaedros, icosaedros, dodecaedros e outras geometrias esféricas complexas, ver Figura 1 (Lotufo e Lopes, 1981).

Segundo Joel Rosnay, com a repetição de formas geométricas em proporções harmoniosas, formam-se espirais, formas estas que produzem padrões essenciais à sustentação da vida. 0 embrião humano, por exemplo, apresenta uma forma espiral, que vai desenrolar-se dentro do útero em um movimento espiralado, assim como um broto de samambaia. Este autor apresenta organizações complexas que se formam a partir de leis simples e usa como exemplo as estruturas fractais:

As formas espirais estão relacionadas aos processos da vida, observados na forma espiralada em dupla hélice encontrada no DNA, que segundo Bueno, representa uma estrutura fundamental para toda a biologia e desvela a importância da forma desde o nível de complexidade mais elementar dos seres 


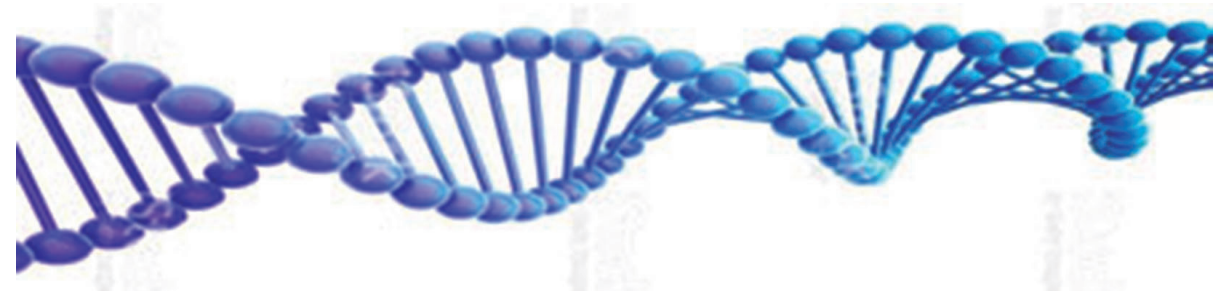

Figura 2: Estrutura espiral do DNA humano.

Fonte: Rodriguez, 2016.

vivos: um reservatório adequado para a transmissão de informações referentes à sua morfologia e às funções biológicas dos seres vivos (Bueno, 2000).

Autores que pesquisam os princípios da organização psico-motora humana como Piret e Béziers (1992) e Godelieve (1995), propõem que os nossos movimentos de braços e pernas são espiralados; o nosso erguer é espiralado em unidades de coordenação e em padrões de comportamento onde as formas de agir se expressam entre o espiralado para fora e o espiralado para dentro, ou em volta do próprio eixo, ou ainda uma parte do corpo para fora e a outra para dentro. Podemos observar na Figura 3 alguns princípios organizacionais da estrutura do corpo humano e suas formas espiraladas.

Piret e Béziers (1992) apresentaram movimentos cotidianos do corpo humano, como flexionar e estender o braço ou a perna, que visualizamos como simples dobradiças, na verdade, acontecem como reflexo das rotações iniciadas nas articulações, que são esféricas. Tais características esféricas geram comportamentos elípticos no movimento global de enrolar e desenrolar, que são para as autoras os modos fundamentais da coordenação motora.

Através de uma analogia com uma peça de roupa sendo torcida, as autoras demonstram que o dobrar é consequência da tensão que se desenvolve à medida que o tecido é torcido em direções opostas, até que haja a flexão, assim como acontece nas rotações do ombro e da mão que se enrolam em direções opostas até que o cotovelo se dobre, conforme mostra a Figura 4 (Victor, 2010).

Kenneth Snelson, artista norte-americano, desenvolveu o sistema estrutural de tensão integral (tensegrity) combinando madeira laminada e fios de nylon, em fins da década de 40. Snelson foi pioneiro na construção de grandes esculturas tensegrity combinando materiais rígidos de metal e materiais flexíveis em aço, ver Figura 5 (Snelson, 2012). Kenneth Snelson aplicou o termo floating compression (compressão flutuante) para descrever este sistema estrutural gerado pela combinação de barras rígidas em compressão e malhas flexíveis em tensão, configurando estruturas autoportantes em estado de equilíbrio. A palavra tensegrity foi criada por Buckminster Fuller e significa a combinação das palavras tensão (tensional) e integridade (integrity). Estruturas tensegrity são formadas por redes flexiveis contínuas submetidas a forças de tração e barras rígidas descontínuas submetidas a forças de compressão. Essas estruturas funcionam em sinergia a partir da polaridade positivo e negativo. Snelson desenvolveu esculturas a partir das armações de pipa (kite-frames), cruzando barras em forma de $X$ estabilizadas por perímetros de cabos. Snelson desenvolveu tensegrities a

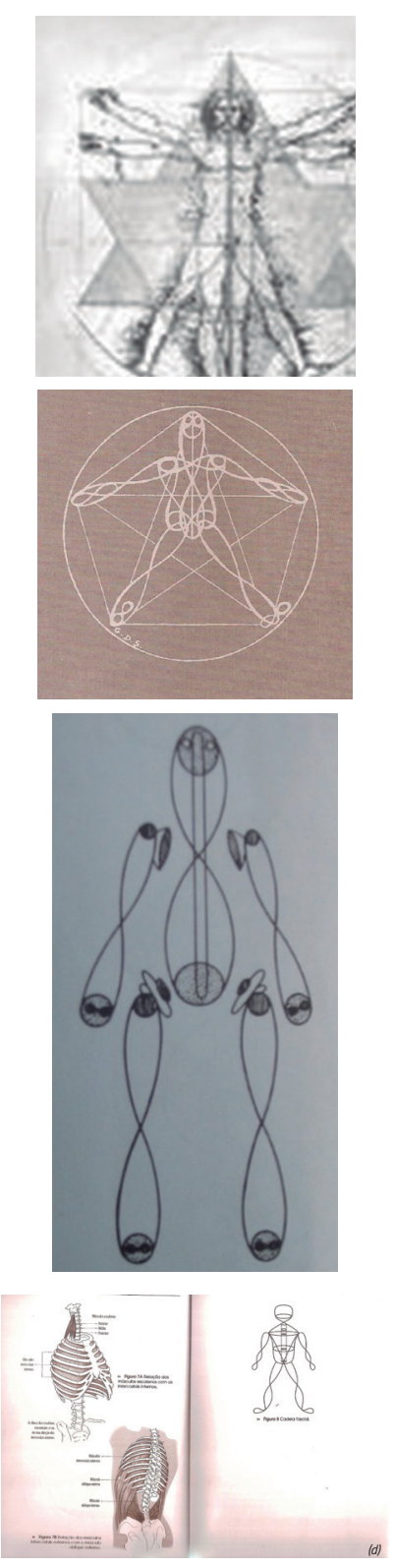

Figura 3: Princípios de organização estrutural do corpo humano em formas espirais. (a) Estudo do corpo humano por Leonardo Da Vinci. (b) Estudo de Godelieve Struff. (c) Característica das unidades de coordenação espiraladas, segundo Béziers. (d) Estudo do movimento global espiralado, segundo Godelieve. 


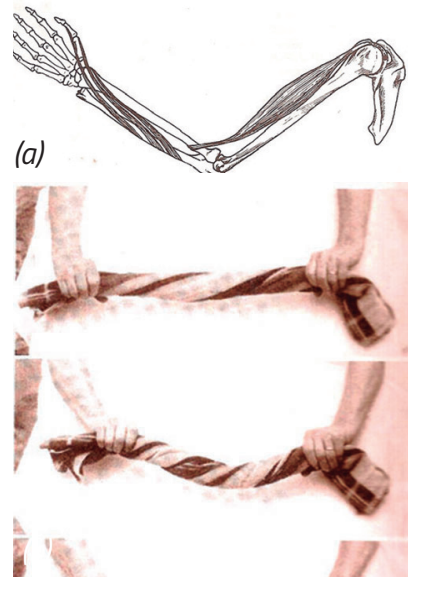

Figura 4: (a) Padrões esféricos das articulações. (b) Forças de torção provocando tensões que geram flexão, Piret e Béziers.

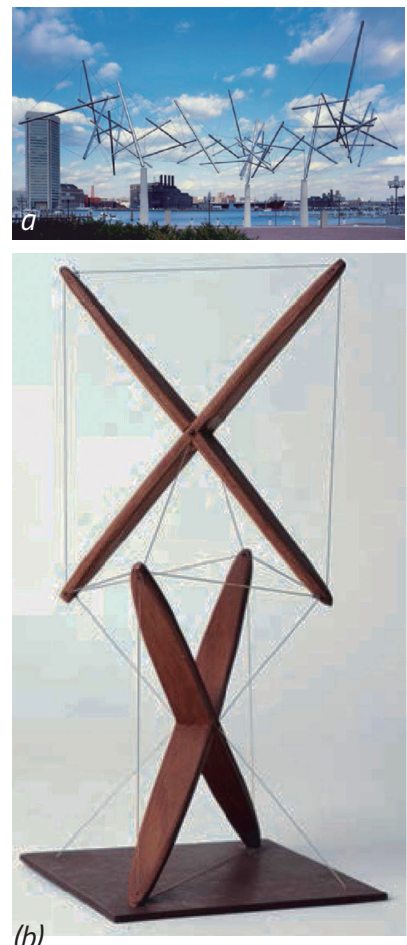

Figura 5: Esculturas de Kenneth Snelson. (a) WoodX-Column, 1948. (b) Easy Landing.

Fonte: Baltimore, 1977

Figura 6: Padrões construtivos aplicados ao tensegrity. (a) Armação da pipa: o prototensegrity (b) Células trançadas presentes na arte da cestaria. partir da livre combinação de barras no espaço, cujo funcionamento a partir de polaridades se assemelha ao magnetismo.

Os estudos de Keneth Snelson sobre padrões construtivos trançados o levaram a afirmar que a cestaria é a mãe das estruturas tensegrity. Elementos flexíveis constituem ligações entre as partes até alcançar a forma como um todo, revelando de modo bastante direto as propriedades universais geométricas das estruturas naturais, ver Figura 6 . Snelson (2012) explica que dois filamentos que se cruzam e formam um $X$, onde dois ângulos são criados em suas diagonais e na dinâmica do sistema, um dos ângulos cria um giro para a direita e o outro, simetricamente, para a esquerda. Segundo o autor, esses giros são equivalentes ao magnetismo, com suas polaridades positivo e negativo, formando uma dualidade que ocorre em cada cruzamento, um fenômeno helicoidal que determina como conectá-las a um outro cruzamento (Victor, 2008).

Em meados da década de 1990, os autores Ingber, Levin, Swanson e Flemons realizaram estudos sobre os sistemas de tensão integral nos organismos vivos. A fim de compreender a relação estrutura-função no corpo humano, vários pesquisadores recorreram aos princípios arquitetônicos da tensegridade para aplicá-los ao entendimento da geometria que estrutura e ordena a funcionalidade do sistema corporal dos vertebrados.

Swanson nos relata que as pesquisas realizadas nos últimos 25 anos demonstraram que os sistemas em biotensegridade possuem princípios construtivos que podem demonstrar a relação estrutura-função mecânica não somente em todas as escalas de tamanho no corpo humano, como também a nível celular, permitindo que a célula detecte mecanicamente seu ambiente e converta sinais mecânicos em mudanças bioquímicas. Quando aplicada aos princípios da medicina osteopática, a biotensegridade fornece uma compreensão conceitual da organização hierárquica do corpo humano e explica a capacidade do corpo de se adaptar às mudanças (Swanson, 2013).

Segundo Ingber, uma enorme variedade de sistemas naturais - incluindo átomos de carbono, moléculas de água, proteínas, vírus, células, tecidos, e até mesmo o ser humano - são construídos e organizados em tensegridade e, por isso, são chamados de biotensegrity. A estrutura corporal é compreendida como uma estrutura tensionada autoportante (que não precisa de apoios para se erguer) em um campo contínuo de tensão, realizado pelos tecidos flexíveis, ou seja, pelo sistema mio-fascial - músculos, tendões, ligamentos e fáscias - e por um campo descontínuo em compressão, representado pelos ossos, também conhecido como tecido ósseo ou sistema esquelético." (Ingber, 1998).

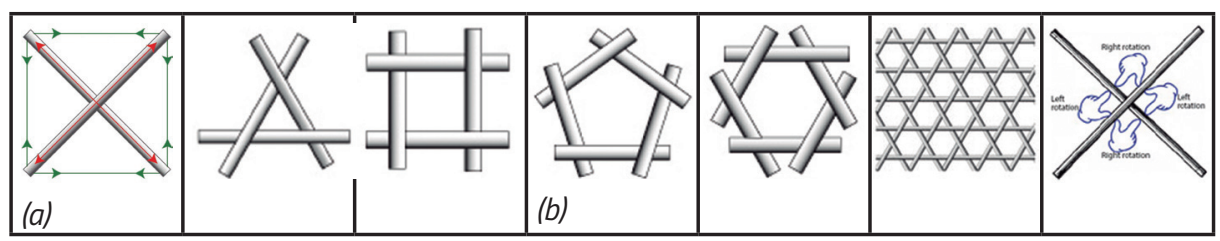


Em seus estudos, Flemons desenvoveu modelos esquemáticos de partes do corpo humano aplicando o sistema estrutural tensegrity. 0 autor analisa as estruturas articulares no corpo e explica como elas podem ser melhor compreendidas usando princípios de tensegridade, conforme mostra a Figura 7.

Thomas Myers, baseia-se nos estudos de Ida Rolf, desenvolvendo e apresentando os "trilhos anatômicos" trazendo contribuições importantes ao definir caminhos de tensão que percorrem todo o corpo, dividindo-os em linhas anatômicas em tensegridade, sendo a principal delas a linha espiralada. Ao conectar os músculos a partir da fáscia, Myers inspirou-se no trabalho do antropólogo Raymond Dart, onde ligava os músculos do tronco em um arranjo de espiral duplo, conforme a Figura 8.

\section{PESQUISA E APLICAÇÃO DE ESTRUTURAS AUTOPORTANTES DE BAMBU E MEMBRANAS TÊXTEIS}

Para apresentar nossas atuais pesquisas sobre estruturas autoportantes biotensegrity, vamos descrever algumas das experiências conduzidas no Laboratório de Investigação em Livre Desenho - LILD, antigo LOTDP, do Departamento de Artes \& Design da PUC-Rio. No LILD, pesquisamos técnicas para construir estruturas de biomateriais, geometrias, formas e princípios estruturais que regem as organizações físico-químicas que a vida produz. Desenvolvemos pesquisas com modelos físicos utilizando métodos experimentais.

Durante os últimos 30 anos, temos desenvolvido metodologias ativas para pesquisa, produção e aplicação social de sistemas estruturais com padrões inspirados em formas da natureza, capazes de reproduzir dinâmicas encontradas nos seres vivos, mais econômicas e apropriadas para novas estruturas de engenharia, que consideram o ciclo de vida dos objetos, desde a sua fabricação ao pós-uso dos materiais. Temos desenvolvidos tecnologias construtivas a partir de sistemas estruturais tensionados, sistemas autoportantes e estruturas com ligações flexíveis aplicados nas áreas da arquitetura, design, engenharia e saúde, contribuindo para a formação de um quadro multiqualificado em uma perspectiva transdisciplinar. Nesse trabalho apresentamos resultados de pesquisas interdisciplinares unindo a engenharia e o design, orientando aprendizados e aplicativos para o desenho de produtos, para construções ecológicas e para a área da saúde.

Metodologias ativas nos processos de investigação, produção e aprendizagem são o que definem o modus operandi do LILD. Cognição corporificada seria, talvez, o termo utilizado pelas neurociências para dizer em poucas palavras a forma como conduzimos nossa metodologia de pesquisa. Não é um conteúdo programado, é algo que se apreende com os sentidos, com o fazer, com o fazer junto, com os dedos, com as mãos e com o corpo. O processamento cognitivo se adentra em nossos gestos, pensamentos, ações, corporificando-se, tornando comum ao nosso agir. As mãos percebem coisas que nosso cérebro irá entender a partir da manipulação de materiais naturais. Segundo Saramago, os dedos, suas pontas, possuem pequenos cérebros. E é com esses pequenos cérebros que trabalhamos a priori, e é no processo do fazer que várias nuances da
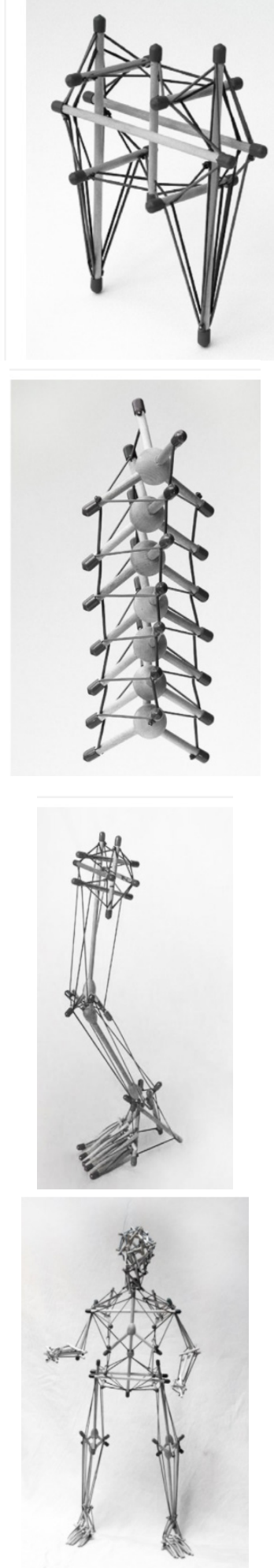

Figura 7: Modelos que demonstram o sistema de biotensegridade no corpo humano. 


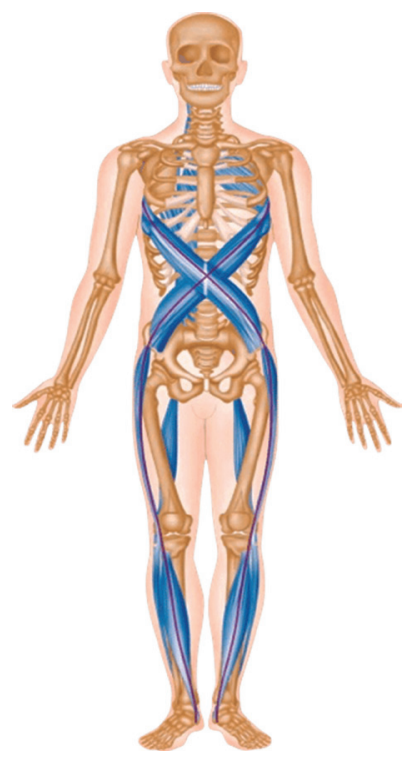

Figura 8: Linha miofascial espiralada.

Fonte: Myers, 2003.

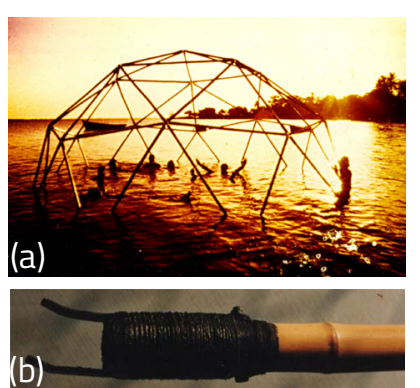

Figura 9: Protótipo de estrutura geodésica de bambus tubulares com juntas pontuais. (a) Geodésica aplicando juntas pontuais na Lagoa de Araruama-RJ. (b) Conexão pontual de aço, sisal e betume experiência são apreendidas pelos sentidos, para que só depois se possa ter uma compreensão a nível cortical do que se tornou aprendizado (Saramago, 2000). Assim, aprendemos que a prática de fazer objetos é essencial para o aprendizado. 0 título de Livre Desenho aponta para o sentido de estimular a criação e a imaginação investigando o que é primordial no gestual do homem em sua relação com os objetos que manipulamos e construímos. São utilizados materiais pouco processados, próximos ao seu estado natural, gerando economia nos meios de produção, redução no consumo de energia e baixo impacto ecológico. São desenvolvidas pesquisas visando aplicações práticas do bambu, da terra crua e de fibras naturais tais como o algodão, a piaçava, o sisal, o coco, entre outras, em construções leves e econômicas com aplicação imediata de seus resultados no meio físico e social, junto às comunidades envolvidas.

Neste sentido, prática e teoria se completam, dando suporte à percepção e ao entendimento geométrico e construtivo do que está sendo pesquisado, evitando a alienação dos agentes em relação aos processos produtivos. A construção de modelos em pequena escala para o estudo e o desenvolvimento são métodos de investigação e de compreensão da relação entre forma, organização, estrutura e função, que ajudam a desenvolver o aparelho cognitivo dos pesquisadores através da prática artesanal e da prototipagem com matérias acessíveis, acrescentando variáveis intuitivas ao processo de elaboração racional, favorecendo insights criativos e procedimentos inovadores no desenho de estruturas.

Em 1992, foi desenvolvido no LILD uma estrutura geodésica empregando colmos de bambu e conexões pontuais em aço ligadas por um compósito de sisal e betume conforme mostra a Figura 9 (Ripper et al., 1995). Procedimentos de montagem e desmontagem da estrutura apresentaram desgaste acelerado das peças componentes em função das juntas pontuais rígidas desenvolvidas. Visando o desenvolvimento de estruturas mais acessíveis e capazes de absorver melhor sobrecargas provenientes de forças de montagem/desmontagem e forças de uso, foi desenvolvido um domo geodésico aplicando o sistema estrutural tensegrity, utilizando conexões excêntricas em giro, conforme observamos na Figura 10 (Moreira et al., 2003). 0 sistema foi insprirado nos modelos tensegritoy desenvolvidos por Kittner e Quimby (1988).

O desenvolvimento de sistemas tensionados aplicando colmos de bambu como elemento estrutural, nos levou ao estudo e desenvolvimento das estruturas tensegrity. São estruturas formadas por elementos que se conectam, se erguem, se sustentam, se equilibram e se integram em formas espaciais a partir do equilíbrio entre forças de tensão e forças de flexo-compressão aplicadas em seus membros estruturais constituintes, feitos geralmente de tubos de bambu, cabos e membranas têxteis. Essas estruturas apresentam tecnologias acessiveis, processos simplificados de fabricação, montagens leves e um amplo potencial de sustentabilidade na área do desenho de produto e da construção civil.

As Figuras 11, 12 e 13 apresentam modelos e protótipos de estruturas tensegrity desenvolvidos no LILD entre as décadas de 90 e 2000.

Foram desenvolvidas ponteiras em materiais rígidos, tais como aço e madeira, e ponteiras em materiais flexíveis, tais como lonas e malhas têxteis de fibras sintéticas, para a construção de estruturas tensegrity visando uma melhor 
distribuição de esforços no topo das barras de bambu (Moreira e Ripper, 2014). Uma série de protótipos foi desenvolvida no LILD entre os anos de 1995 e 2005 com esta finalidade, conforme mostra a Figura 14.

Bambutec, empresa originada dentro do LILD e graduada pelo Instituto Genesis da PUC-Rio, desenvolveu uma estrutura tensegrity para eventos itinerantes realizados no Rio de Janeiro e São Paulo (Seixas, 2009). A estrutura media 8 x $6 \mathrm{~m}$ em um total de $48 \mathrm{~m}^{2}$ de área, apresentando uma montagem ultraleve conforme apresentado na Figura 15. A estrutura foi analisada posteriormente pelo Laboratório de Sistemas Estruturais - LASE da Escola de Engenharia da UFMG, parceira do LILD no desenvolvimento da pesquisa apresentada neste artigo. A Figura 16 apresenta resultados da análise da cobertura aérea aplicando estrutura tensegrity através do Método dos Elementos Finitos (MEF) utilizando o programa SAP2000 (Moreira et al., 2010).

Simultaneamente, desenvolvemos estudos sobre estruturas reticuladas pantográficas utilizando colmos de bambu e cabos têxteis de fibras sintéticas. Estas estruturas adaptáveis foram inspiradas nas habitações nômades do deserto de Gobe na Mongólia, popularmente conhecidas com Ger ou Yurt (Khan e Easton, 1979). A partir de experiências com materiais flexíveis, elaboramos ligações articuladas gerando conexões com um ou mais graus de liberdade entre as peças estruturais. As ligações apresentaram baixo desgaste mecânico entre os elementos da estrutura, livre de esforços de torção. Estas conexões têxteis articuladas se mostraram apropriadas para estruturas de engenharia (Seixas et al., 2016, Moreira et al., 2017). Estas estruturas se aproximam da constituição da estrutura dos animais vertebrados e são inspiradas na mecânica dos seres vivos. As Figuras 17 e 18, mostram estruturas pantográficas aplicando as conexões flexiveis desenvolvidas.

Em 2014, Bambutec desenvolveu uma estrutura autoportante ultraleve a partir de cascas treliçadas pantográficas, inspiradas no movimento do dorso do tatu, ver Figura 19. A estrutura autoportante foi aplicada na cobertura de um anfiteatro ao ar livre na PUC-Rio. A estrutura cobre uma área de $17 \times 12 \mathrm{~m}$ em um total de $200 \mathrm{~m}^{2}$ e apresenta peso de 1,4 toneladas, isto é, $7 \mathrm{kgf} / \mathrm{m}^{2}$, comparando-se em leveza apenas às modernas estruturas de polímeros avançados. Sua forma foi desenvolvida a partir de retículas pantográficas articuladas, arcos de flexão ativa, membranas acrílicas, suportes articulados em forma de bipés e conexões flexíveis, como mostra o diagrama da Figura 20. A estrutura de cobertura do Anfiteatro foi desenvolvida por meio da sobreposição de cascas treliçadas em uma geometria de forma livre, que permite a entrada de luz natural e de ventilação em um terreno arborizado em declive no clima tropical do Rio de Janeiro. Emprega um método de deformação elástica dos arcos de flexão ativa, que são posteriormente reforçados por tesouras articuladas, capazes de gerar geometrias complexas na formação de cúpulas (Seixas et al., 2017). Aplica conexões flexíveis articuladas, sem a utilização de furos, pregos e parafusos, em um sistema tensionado autoportante que se assemelha ao corpo de um animal vertebrado (Figuras 20 e 21).

A tipologia construtiva aplica métodos de montagem inovadores que consideram o movimento dos módulos estruturais no espaço empregando alavancas e contrapesos aplicando um sistema estrutural ultraleve, que dispensa o uso de guindastes e equipamentos pesados, conforme mostra a Figura 22. 
Figura 12: Objetos tensegrity desenvolvidos no LILD. (a) Painéis expositores. (b) Montagem de berço de bambu e redes. (c) Berço de bambue redes

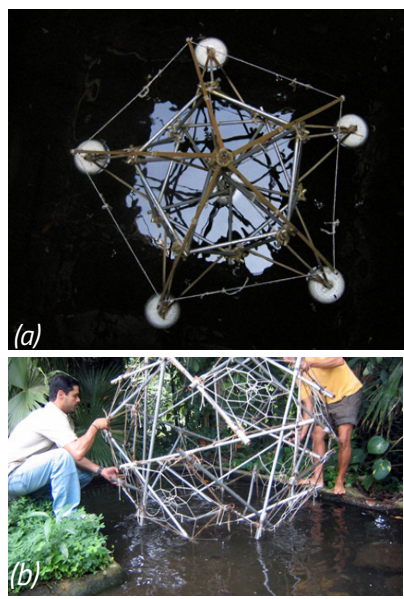

Figura 13: Modelos tensegrity desenvolvidos no LILD aplicados no meio líquido (a) e (b) Modelos de icosaedros flutuantes aplicados sobre o espelho d'água.

Fonte: Ripper et al., 1999.

Figura 17: Movimento pantográfico de estrutura treliçada plana empregando juntas flexíveis.

Figura 18: Movimento articulado de estrutura treliçada tridimensional empregando juntas flexíveis.
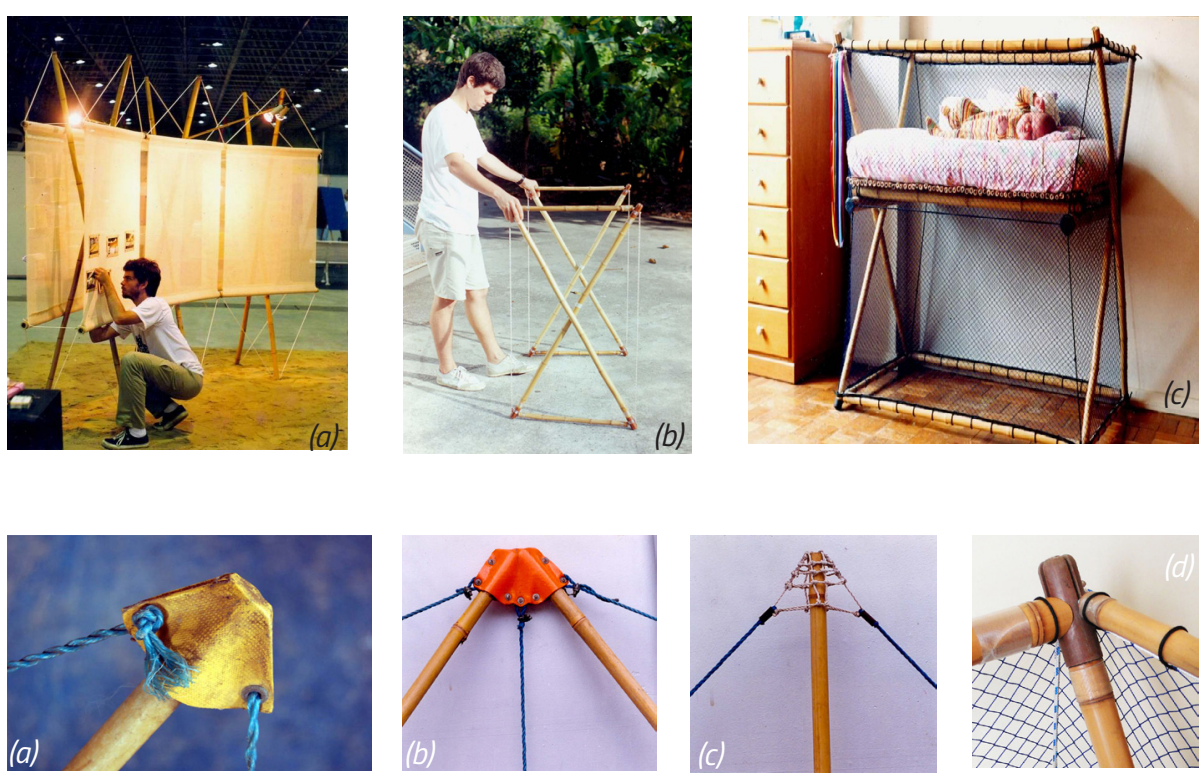

Figura 14: Ponteiras estruturais aplicadas em estruturas tensegrity. (a) Ponteira em lona têxtil de PVC e poliéster. (b) Ponteira em lona têxtil de PVC e poliéster para conexão articulada de 2 barras de bambu. (c) Ponteira flexivel em rede de polietileno trançada. (d) Ponteira rígida em madeira da espécie Manilkara spp. e malha de poliamida.

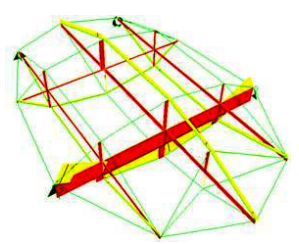

(a)

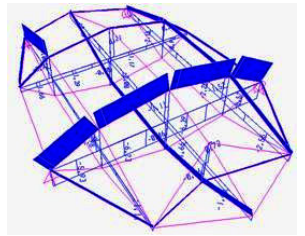

(b)

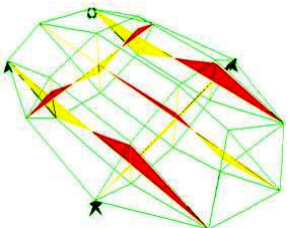

(c)

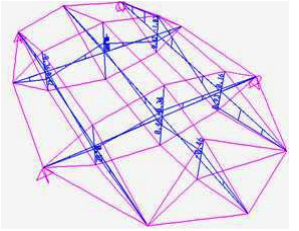

(d)
Figura 16: Análise estrutural de cobertura aérea tensegrity empregando MEF no programa SAP 2000 (LASE-UFMG, 2010). (a) (b) Forças axiais nas barras. (c) (d) Momentos fletores.
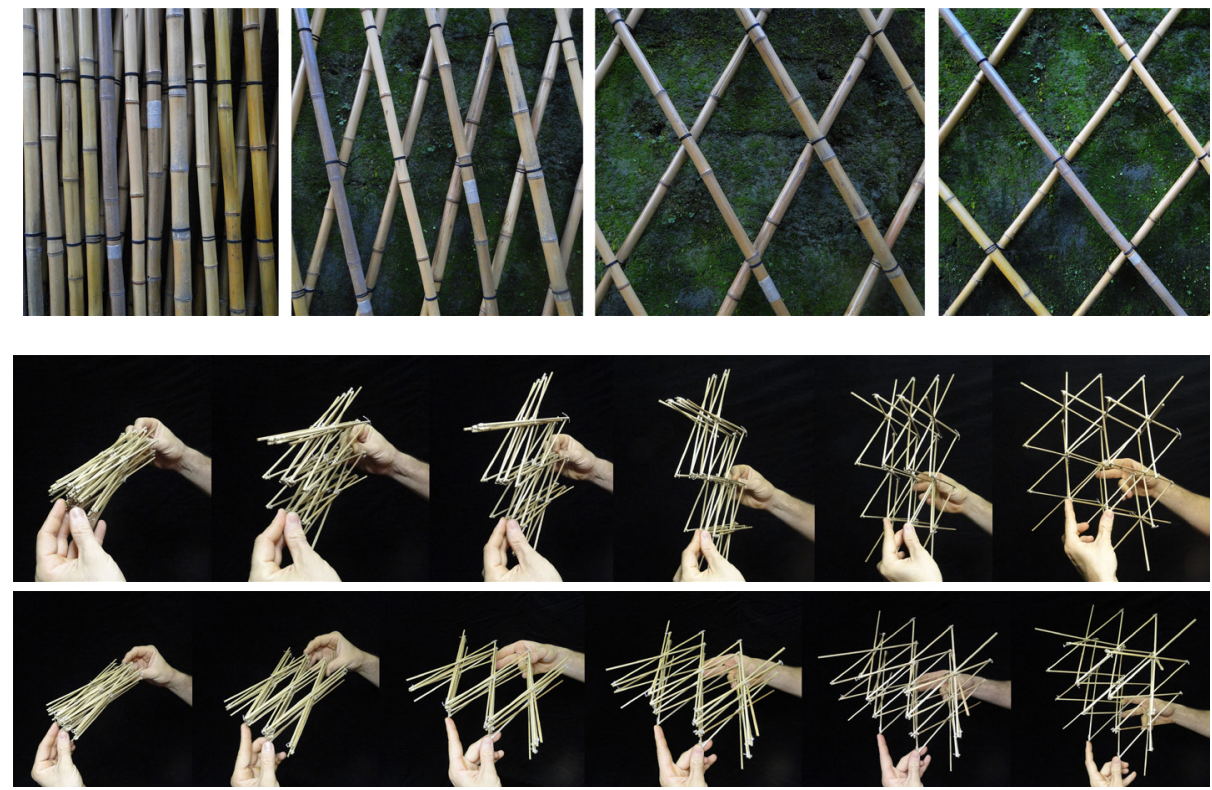

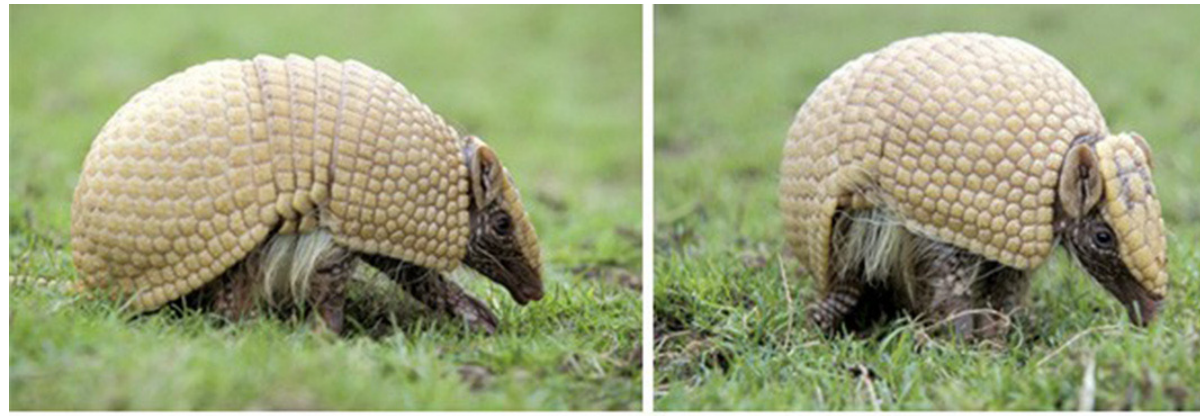

Figura 19: Movimento articulado do dorso do tatubola.

Fonte: Associação Caatingal Mark Payne-Gill/NaturePL.
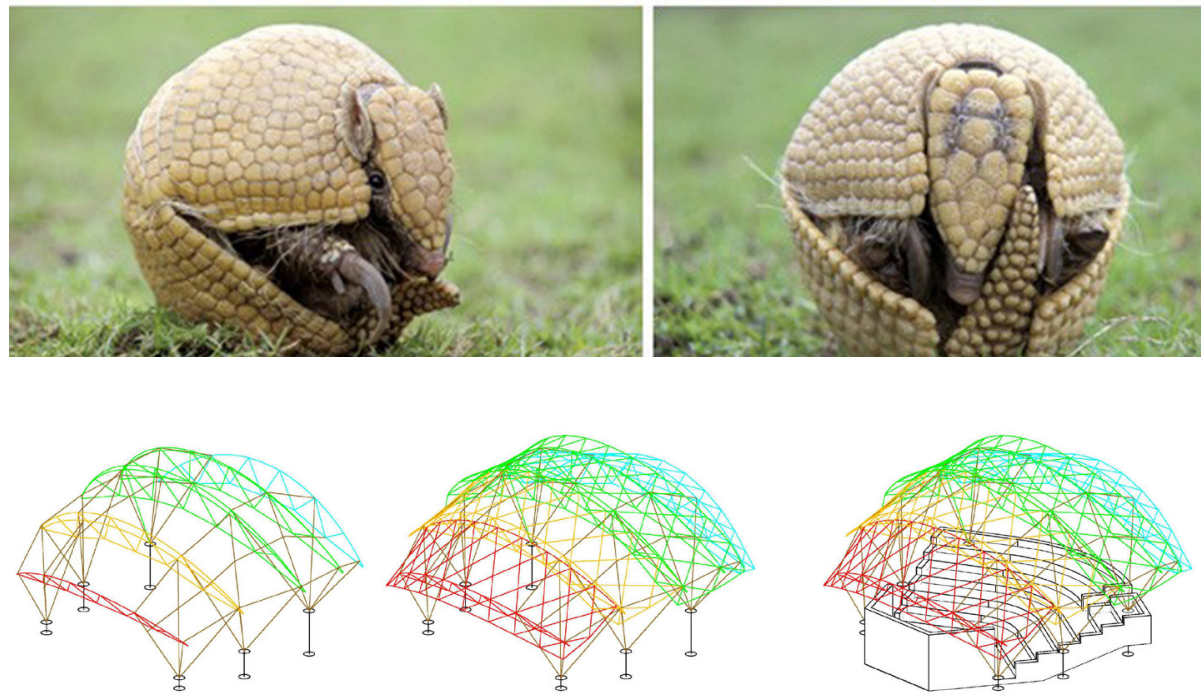

Figura 20: Modelo em CAD de estrutura de cobertura sobre Anfiteatro ao ar livre. Elementos estruturais em arcos de flexão ativa, retículas pantográficas tensionadas por membranas acrilicas e suportes articulados tocando o solo. Fonte: Bambutec, 2014.

\section{MODELOS DE PESQUISA E APRENDIZAGEM ATIVA APLICANDO ESTRUTURAS TENSEGRITY E BIOTENSEGRITY}

A presente pesquisa em estruturas tensegrity e biotensegrity partiu da necessidade de superar o paradigma clássico do aspecto duro e fragmentário do tradicional modelo biomédico, representado por modelos de corpo humano rígidos e construídos a partir de uma mecânica estrutural reducionista. Por exemplo, a utilização de um eixo onde se inserem as vértebras para representar a espinha vertebral, ou um sistema de dobradiça iguais aos utilizados em uma porta para representar a articulação do joelho, são soluções de representação do corpo humano correspondentes a um paradigma mecanicista ultrapassado. Tais modelos nos levam à compreensão de uma rigidez e uma estaticidade que não correspondem à forma construtiva e à dinâmica funcional que as formas da natureza adotam nas suas relações internas e externas, como por exemplo, forças superficiais em uma membrana (relações internas) e reações de apoio de um corpo mediante à força da gravidade (relações externas), que são relações físicas complexas. Por conseguinte, estes modelos induzem equívocos quanto à compreensão da tridimensionalidade e da geometria construtiva que ordena a estrutura corporal do humano e dos animais vertebrados, e, consequentemente, a equívocos quanto a forma de diagnóstico e tratamento.
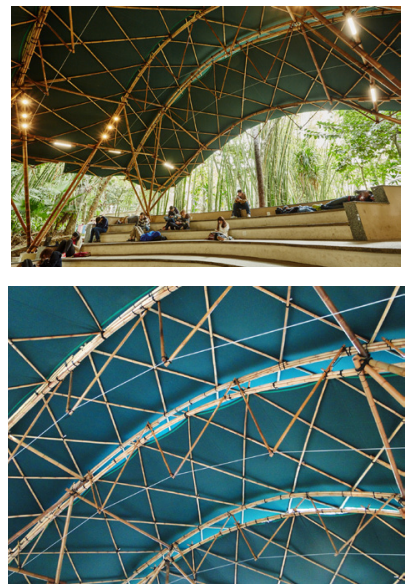

Figura 21: Vista interna da estrutura do Anfiteatro da PUC-Rio, empregando tubos de bambu, membranas acrilicas e conexões flexíveis em cabos de poliéster. Fonte: Bambutec, 2014. 

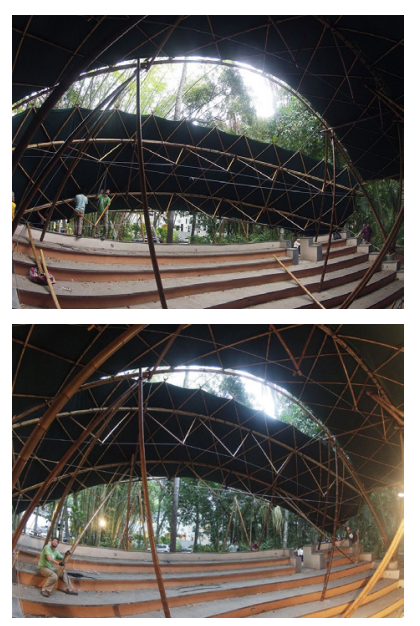

Figura 22: Procedimento de montagem da estrutura de cobertura do Anfiteatro, que apresenta a elevação do módulo de casca treliçada reforçada por arcos de flexão ativa. A estrutura é soerguida por elevadores móveis e alavancas em um sistema adaptável para o terreno em declive do Anfiteatro.
Temos pesquisado modelos do corpo humano apoiados em um paradigma sistêmico visando uma maior compreensão da dinâmica do corpo dos animais vertebrados e dos sistemas vivos. As estruturas autoportantes desenvolvidas são capazes de explicar, demonstrando visual e sensorialmente os princípios de plasticidade, integridade e solidariedade funcional, entre outros princípios que funcionam em cadeias integradas de movimento. Facilitam o reconhecimento do corpo humano como um sistema integrado de tensões onde a organização da sua estrutura se dá por meio de um complexo inter-relacionamento entre os componentes estruturais que se conectam e se formam, de tal modo que o posicionamento de elementos em uma parte do corpo altere o arranjo e o movimento em outra parte. Sendo assim, podemos explicar como o corpo humano tende a compensar a perda de mobilidade de uma parte do corpo e o aparecimento de sintomas em outra parte. Esta nova forma de abordagem e evolução no reconhecimento do corpo como sistema, traz consigo novos métodos e meios de avaliação da dinâmica corporal, os quais regem novas formas de entendimento, leitura e diagnóstico da dinâmica e do estudo da funcionalidade do movimento humano, conduzindo a práticas de intermediação e tratamento dos sintomas. Tais mudanças nas formas de ver e pensar o corpo, originam por sua vez, novas formas e técnicas de transformá-lo em busca de melhor funcionalidade global. Estudos e trabalhos mais recentes nesse sentido, encontram-se carentes de modelos que expliquem o complexo funcionamento mecânico do corpo humano. Torna-se impossivel saltar para um novo patamar interpretativo, embasado nos modelos que representam uma estrutura corporal rígida e que não possui as qualidades que caracterizam o nosso sistema, tais como, maleabilidade, plasticidade e equilíbrio de tensões, que definem nossa arquitetura corporal no espaço físico. Torna-se iminente desenvolver modelos que simulem essa dinâmica para aplicá-la ao ensino, a fim de estabelecer um novo paradigma de ensino-aprendizagem do corpo, a fim de permitir ver e avaliar, de um novo ângulo, os problemas e suas causas. (Victor, 2010). Foi nesse contexto que se desenvolveu no LILD a pesquisa de tese Design para Saúde.

Os resultados e desdobramentos que apresentamos aqui, originou um o Grupo de Estudos em Biotensegrity, sediado no LILD, unindo as áreas do design, engenharia e medicina.

Uma organização corporal saudável é construída em tensegridade (tensegrity), onde nossos ossos atuam como espaçadores na rede formada pelo tecido conjuntivo que é um tecido fascial contínuo. Nenhum elemento rígido se encontra em contato com o outro elemento rígido, fornecendo-Ihes apoios rígidos. Os elementos estruturais são conectados por malhas de cabos, que fornecem apoios flexíveis. A Figura 22 apresenta estruturas geodésicas tensegrity de barras de bambu descontínuas e malhas tensionadas contínuas, caracterizando um estado mecânico de tensão integral. Esta organização física autoportante estável é correspondente à organização saudável do corpo humano e dos corpos dos animais vertebrados, sendo capaz de assimilar forças especiais, impactos e cargas dinâmicas.

Após desenvolver uma série de estudos biológicos testados em laboratório, Ingber concluiu que seus resultados apoiam fortemente o potencial valor clínico dos sistemas biomiméticos de engenharia que recriam interfaces funcionais de tecidos vivos e experimentam estresses mecânicos fisiológicos. 
"Um dos princípios de design biológico mais fundamentais que descobrimos é claramente o uso da arquitetura de tensegridade, que observamos em praticamente todas as escalas de tamanho na hierarquia da vida".

0 autor se dedica a projetar e fabricar materiais biomiméticos que utilizam princípios de tensegrity usando técnicas de design e fabricação. (Ingber, 2012).

Nossas vértebras são conectadas por músculos cujo funcionamento é similar ao dos cabos de estruturação, tensão, direcionamento e reforço que encontramos nos mastros compostos das embarcações. Segundo Frei Otto, "a estrutura dos corpos dos animais são estruturas híbridas compostas de elementos resistentes à flexão e à compressão (ossos, espinha, esqueleto), que estão rodeados de elementos resistentes à tração, como são os músculos, as veias e a pele, que formam uma estrutura parecida com a dos mastros compostos" (Roland, 1965). Os elementos rígidos estão conectados por tecidos flexiveis que funcionam como "transportadores" dessas qualidades de uma vértebra a outra, nesse caso, e, de uma parte constituinte do corpo à outra no que se refere a todos os tecidos que formam a estrutura corporal. A Figura 24 apresenta modelos de mastros compostos desenvolvidos pelo grupo coordenado por Frei Otto no Instituts für leichte Flächentragwerke (IL) da Universidade de Stuttgart (Roland, 1965).

Inspirados nas pesquisas desenvolvidas por Frei Otto na Universidade de Stuttgart, desenvolvemos modelos de mastros compostos aplicados em estruturas temporárias e modelos didáticos do corpo humano. Os mastros compostos desenvolvidos são longarinas de bambu entre 6 e $8 \mathrm{~m}$ de comprimento, reforçadas por cruzetas transversais de bambus e cabos têxteis acopladas ao longo da peça, contraventando e aumentando a resistência à flambagem dos elementos esbeltos de bambu, ver Figura 25. Desenvolvemos conexões em aço aplicadas nas extremidades da estrutura, de forma a distribuir forças de compressão no topo das peças de bambu e distribuir as forças de tração em uma rede contínua de tensão integral. Empregamos cabos têxteis de poliéster e polipropileno pré-tensionados a partir das medidas aferidas nos modelos físicos realizados, conforme mostram as Figuras 25 e 26 (Bambutec, 2009).
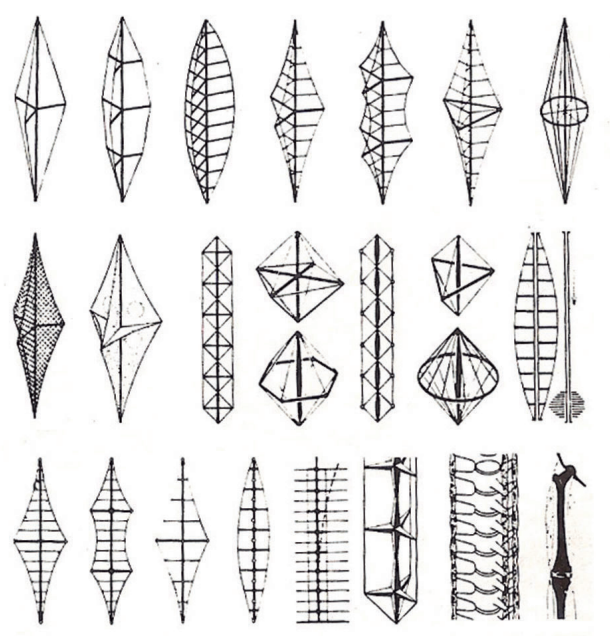
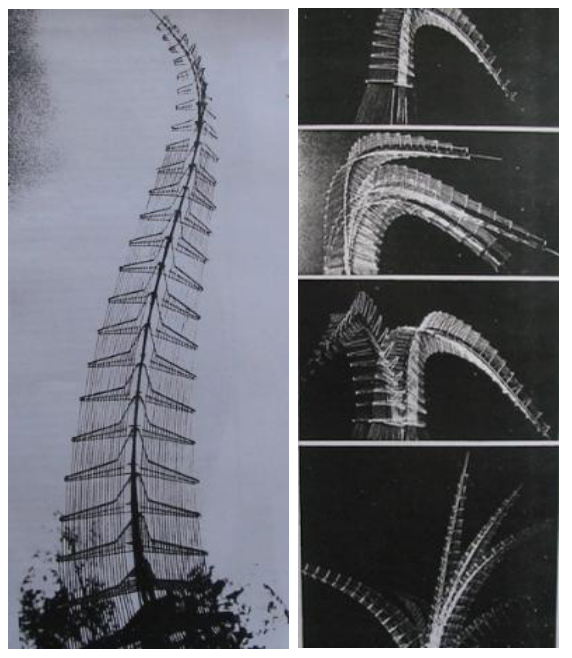
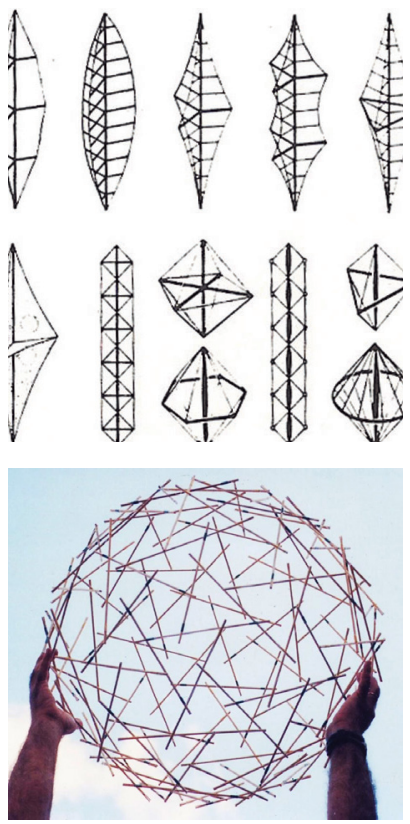

Figura 23: Modelos de estruturas geodésicas em sistema de tensão integral (tensegrity) desenvolvidas no LILD (a) Icosaedro tensegrity. (b) Geodésica tensegrity frequência 2V.

Figura 24: Modelos de mastros compostos desenvolvidos por Frei Otto no IL da Universidade de Stuttgart.

Fonte: Roland, 1965. 
Figura 25: Mastros empregados na construção de um estande de exposição, empregando longarinas de $8 \mathrm{~m}$ de comprimento e diâmetro das longarinas de $60 \mathrm{~mm}$. Fonte: Bambutec, 2009.
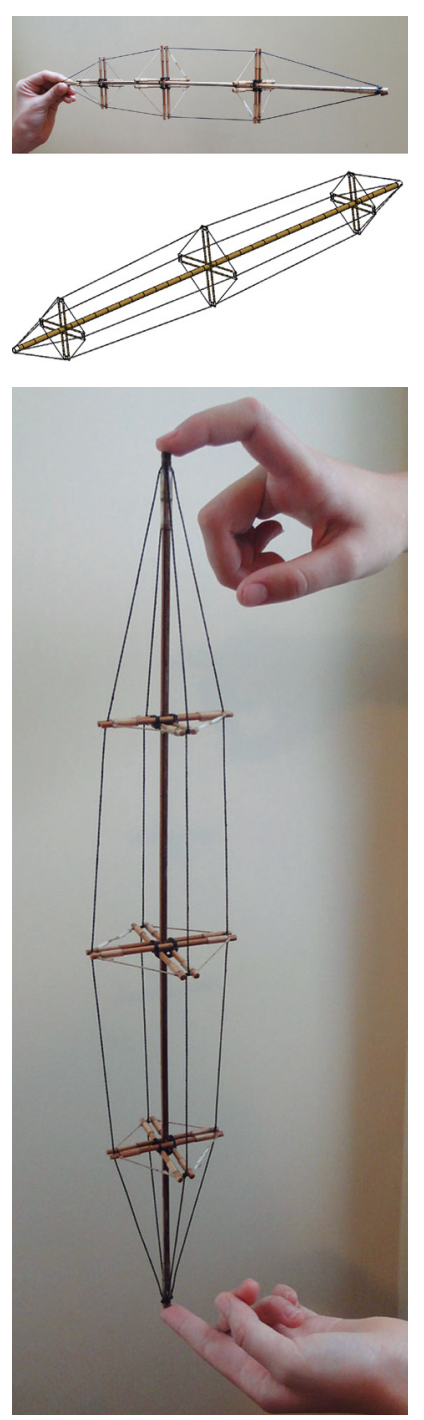

Figura 26: Modelo de mastro composto medindo 6 a 8 metros de comprimento, empregando longarinas de bambu com 60mm de diâmetro.

Fote: Bambutec, 2009.
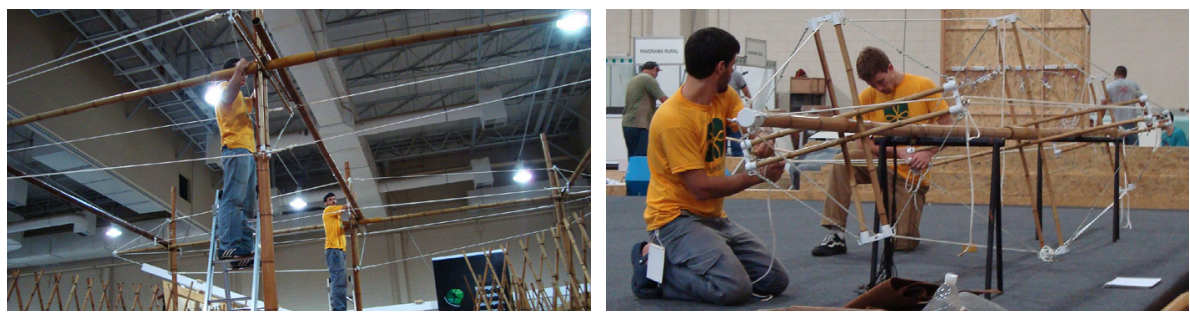

\section{MODELOS DIDÁTICOS DO CORPO HUMANO APLICANDO O SISTEMA BIOTENSEGRITY}

O objetivo desse trabalho foi desenvolver modelos construídos com abordagens estruturais mais aproximadas da estrutura viva, capazes de demostrar informações sobre as relações entre a estrutura e função e de demostrar as cadeias de solidariedade funcional que determinam a dinâmica do corpo humano. A missão é produzir modelos inovadores na medida em que o conhecimento transmitido influencia conteúdos nos processos de raciocínio e cognição quando aplicados às várias áreas de estudo que estudam o corpo humano, modificando desde parâmetros de projeto até formas de diagnosticar e tratar as pessoas. 0 presente estudo aplicou a metodologia de biomimética de modo a alcançarmos formas de representação da estrutura e da biomecânica dos organismos dos vertebrados estudados. Ao invés de começar o estudo da forma a partir de desenhos, a metodologia de reconhecimento da estrutura se deu a partir da própria construção de modelos por meio da mimese da anatomia do corpo humano. Construindo primeiramente as vértebras em hastes bambu, e depois as ligações entre elas em cabos de algodão conectados seguindo as direções e caminhos traçados pela forma das inserções dos músculos observados, conforme descrições estudadas em livros de anatomia e biomecânica, ver Figura 27.

O modelo de espinha vertebral realizado seguindo o projeto construtivo ditado pela própria anatomia, se apresenta como um sistema Biotensegrity, por se estruturar de forma onde nenhum elemento rígido se apoia diretamente no outro, mas que se organiza no espaço gravitacional a partir da tensão estabelecida pelos cabos flexíveis que direcionam e organizam a forma. Essa forma estrutural construída sem os discos intervertebrais nos permite visualizar que o espaço que seria por eles ocupado, é preservado pela direção de tensão e compressão realizados por esses músculos, aqui representados pelos cabos de conexão, ver Figura 28.

Para a ancoragem da espinha vertebral na cintura escapular foi necessário construir um modelo correspondente aos ossos das escápulas e da bacia. Para tanto, foi utilizado um biocompósito de sisal e argila. Para a ligação entre as vértebras e as escápulas utilizando tecido de poliamida, foram construídos cabos representativos dos músculos romboide e elevador da escápula (em amarelo) e os do músculo trapézio (em laranja), conforme a Figura 29. Para a ancoragem na bacia, foram construídos os cabos representativos do músculo quadrado lombar com linhas têxteis de algodão, ver Figura 29. 

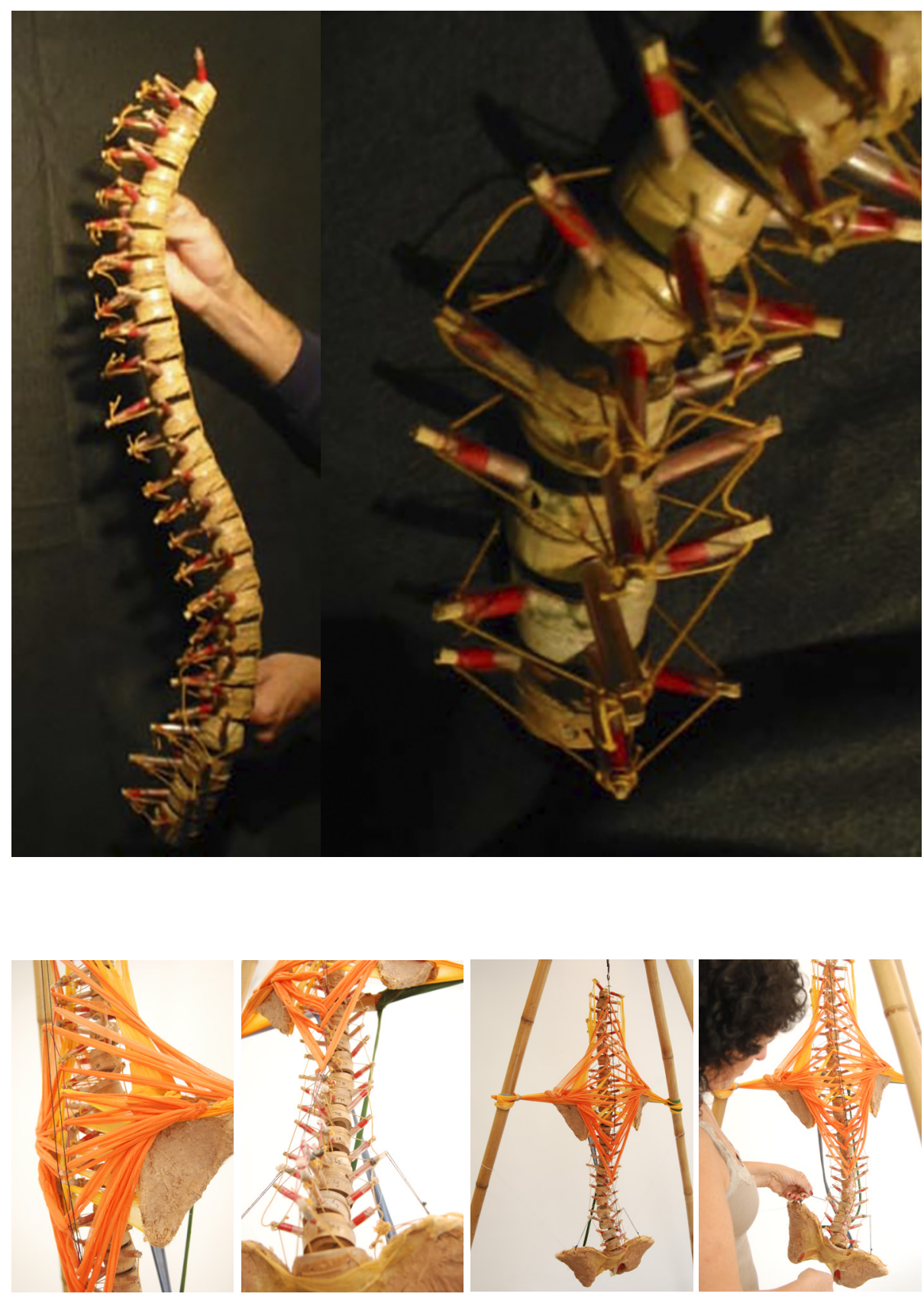

O presente modelo permite visualizar o comportamento do sistema integrado da espinha vertebral e da cintura escapular apresentando suas curvas compensatórias que fluem e repercutem por todo o sistema (Figuras 30 e 31).

\section{ESTUDO DA ESTRUTURA DO DIAFRAGMA}

O modelo da abóbada do diafragma foi desenvolvido a partir da observação do desenho e do mecanismo da água-viva (ver Figura 32), que tem estrutura e 0 movimento de locomoção, análogos ao movimento de inspiração e expiração no corpo humano.
Figura 28: Modelo físico da espinha vertebral utilizando o sistema Biotensegrity.

Figura 29: Modelo da espinha vertebral conectado ao modelo da cintura escapular em sistema biotensegrity. 
Figura 32: Forma da água-viva no meio líquido.
Figura 33: Anatomia da estrutura da água viva e modelos do diafragma do corpo humano.
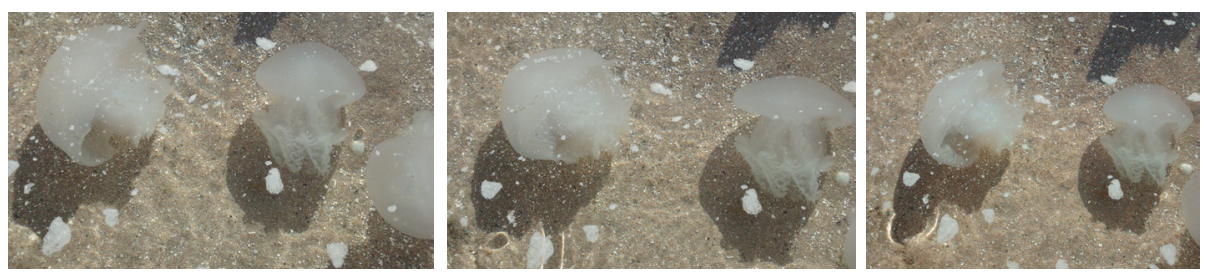

O movimento de expansão ao inflar, abrindo e aumentando o raio entre os tendões, emite uma força de propulsão encontrado no sistema de locomoção da água-viva, que é análogo ao movimento que realizamos ao inspirar, e ocorre no diafragma do corpo humano. 0 movimento do diafragma humano ocorre baixando o centro, expandindo o seu diâmetro e abrindo as costelas, por consequência dos tendões que se encontram inseridos em suas bordas.

Na expiração, os tendões se aproximam, diminuindo o raio entre eles, elevando o centro da estrutura da abóbada do diafragma e aproximando as costelas, devido a ação de fechamento dos tendões que nelas se inserem.

Além disso, para a definição da forma, utilizamos a biomimese da anatomia da estrutura da água-viva e do diafragma do corpo humano, como também nos baseamos no estudo de uma estrutura de cobertura a partir da sobrinha chinesa, desenvolvida no LILD para construção do sistema dinâmico do diafragma, conforme mostra a Figura 33. O resultado é uma estrutura autoportante que apresenta uma geometria formada por arcos de flexão ativos, que geram um desenho propício para que o movimento descrito anteriormente ocorra.

O diafragma possui 17 hastes (feixes de fibras musculares e tendões) que se fixam nas bordas das costelas em cada lado do corpo das vértebras lombares L4 e L5, sendo um em cada lado, próximos aos processos transversos dessas vértebras, indo se inserir no quadrado lombar e no arco da cadeia muscular psoas, ver Figuras 34 e 35.

O estudo da forma, através de sua materialização e prototipagem, gera informações sobre a estrutura e sua dinâmica física, que somente são percebidas durante $o$ ato de construir, formando uma cadeia cognitiva de retroalimentação entre o pensar e o fazer, em um processo cognitivo que se estabelece através de respostas e sensações apreendidos a partir do desenvolvimento dos modelos físicos. 0 uso do modelo aponta para aspectos a serem melhorados em uma nova etapa. Exige uma atualização nos processos
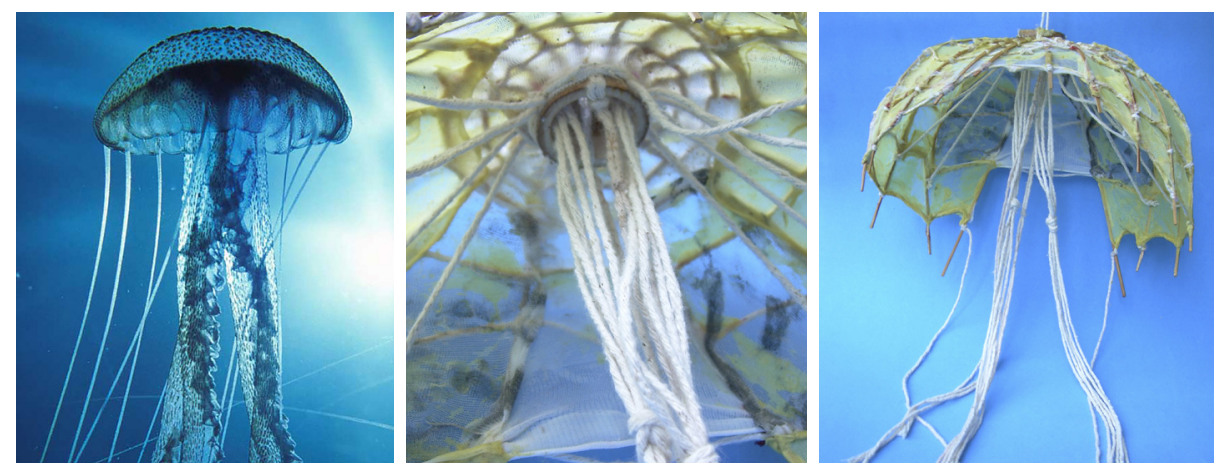

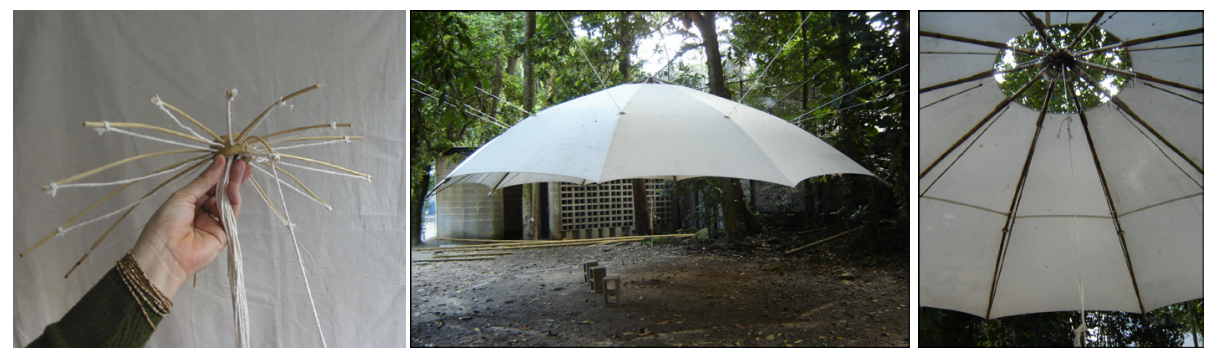

Figura 34: Estudo de estrutura de cobertura a partir da sobrinha chinesa, informando sobre a construção do sistema dinâmico do diafragma.
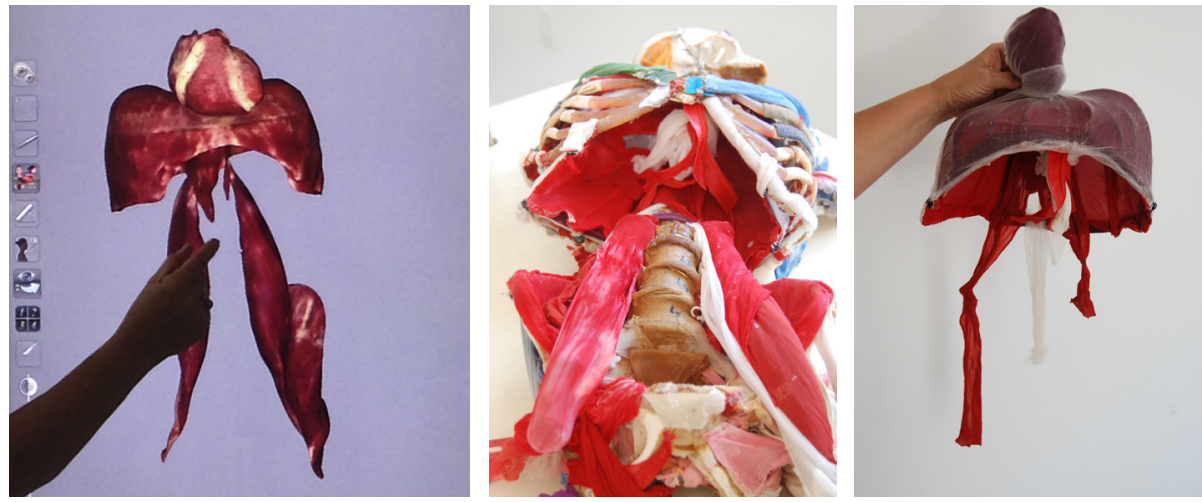

Figura 35: Estudo de conexão do modelo do diafragma ao modelo da espinha vertebral, conectando pela fáscia, ao coração e ao músculo psoas.

e materiais selecionados para a elaboração mais adequada às necessidades de uso. Os sistemas biotensegrity são uma importante contribuição para a compreensão da biomecânica e de sua influencia energética, informacional e vibracional nos organismos vivos, aplicados em modelos didáticos. São capazes de demostrar uma arquitetura e uma dinâmica mais aproximada do corpo humano, apresentando novas perspectivas para profissionais e estudantes que trabalham com o corpo. Na sua utilização compreendemos conceitos e relações estruturais entre forma e função, e também como um movimento ou tensão em uma parte da estrutura pode influenciar a estrutura e o movimento em outras partes. Essas informações implicam nas formas de ver e compreender o corpo humano quando aplicadas a outras áreas do conhecimento, tendo um potencial de inovação quando aplicados nas áreas da indústria de mobiliário, ergonomia, atletismo de alta performance e nas terapias corporais.

\section{CONCLUSÃO}

A compreensão do corpo humano como um sistema biotensegrity, propõe um novo método de compreensão da arquitetura da biomecânica organizacional psico-motora humana. Propõe um novo paradigma de compreensão do corpo humano no âmbito das pesquisas e práticas fisioterapêuticas, capazes de alavancar processos criativos. Pesquisas em andamento vem contribuindo significativamente na transformação do estado de conhecimento, estabelecendo novos modelos mentais de cognição através de modelos físicos, que incentivam processos de inovação quando aplicados em áreas do conhecimento como a arte, arquitetura, design, engenharia e medicina. Novos métodos de ensino, de formulação de objetivos, processos de decisão e estratégias utilizados resultam em novas formas de diagnosticar e tratar o corpo. Estas práticas têm 
originado técnicas aplicadas para transformar o corpo na busca de uma melhor funcionalidade global de profilaxia, de preservação, tratamento, recuperação e inclusão. Novas tecnologias e sistemas flexiveis de engenharia vêm sendo desenvolvidos a partir de biomateriais, aplicados em arquiteturas, objetos úteis e modelos didáticos, configurando um campo de extensão das pesquisas desenvolvidas sobre estrutura tensegrity e estruturas biotensegrity. Modelos estudados inicialmente em âmbito acadêmico, vem gradualmente sendo implementados em aplicativos no meio físico e social, contribuindo para os avanços científico-tecnológicos deste campo interdisciplinar de conhecimento.

\section{AGRADECIMENTOS}

Os autores agradecem aos pesquisadores Ana Branco Nogueira, Ana Freitas Machado, Giuliano Balsini, João Bina, Lucas Alves Ripper, Luís Eustáquio Moreira, Luís Vicente Barros, Marcelo da Fonseca e Silva, Nicolas Gomez e Patrick Stoffel pela importante contribuição dedicada à presente pesquisa. Os autores agradecem ao CNPQ, à CAPES, à FAPERJ e à LUPO pelo apoio concedido no desenvolvimento da presente pesquisa.

\section{REFERÊNCIAS}

BAMBUTEC DESIGN. www.bambutec.com.br (acesso em 20 de Dezembro 2017).

BUENO, A. P. F. Crescimento craniofacial. Rio de Janeiro: ediçcão do autor, 1997.

BUENO, A. P. F. Introdução às bases cibernéticas da ortopedia dentofacial. Rio de Janeiro: Edição Europa, 1991.

BÉZIERS, M. M.; HUNSINGER, Yva. O bebê e a coordenação motora: os gestos apropriados para lidar com a criança. São Paulo: Summus, 1994.

CAPRA, Fritjof. As conexões ocultas: Ciência para uma vida sustentável. São Paulo: Ed. Pensamento-Cultrix, 2002

FLEMONS, Tom http://intensiondesigns.ca

GODELIEVE, D. S. Cadeias musculares articulares: o método GDS. São Paulo: Summus Editorial, 1995

INGBER DE. Cellular tensegrity: defining new rules of biological design that govern the cytoskeleton. J Cell Sci. 1993; 104(pt 3):613-627. http://jcs.biologists.org/ content/104/3/613.long. Accessed April 25, 2012.

INGBER DE. From cellular mechanotransduction to biologically inspired engineering: 2009 Pritzker Award Lecture, BMES Annual Meeting October 10, 2009. Ann Biomed Eng. 2010;38(3):11481161. http://www.ncbi.n/m.nih.gov/pmc/articles/ PMC2913424/?tool=pubmed. (acesso em 25 de Abril, 2012).

INGBER DE. Tensegrity-based mechanosensing from macro to micro. Prog Biophys Mol Biol. 2008;97(2-3):163-179. http://www.ncbi.nlm.nih.gov/pmc/articles/ PMC2570054/?tool=pubmed. Accessed April 25, 2012.

KHAN, L.; EASTON, B. Cobijo. Shelter Publications. Madrid: H. Blume Ediciones, 1979.

KITTNER, C.; QUIMBY, S. Compression-tension strut-cord units for tensile-integrity structures US Patent 4731962, 1988.

KLENK, Frieder.; REINER, Rolf; HAUG, Eberhard; OTTO, Frei. IL 24 Prinzip Leichtbau.

Stuttgart: Karl Krämer Verlag Stuttgart, 1998.

LEVIN SM. The Icosahedron as a Biologic Support System. Proceedings, 34th Annual Conference on Engineering in Medicine and Biology. 1981;23:404.

LOTUFO, V.; LOPES, J.M.A. Geodésicas \& Cia. São Paulo: Projeto Editores Associados, 1aㅡ edição, 1981.

MOREIRA, L.E.; RIPPER, J.L.M.; SILVA, M.F. Técnicas de constituição de objetos tecnológicos e sua aplicação à geração de um domus de bambu tensegrity. Proceedings of the IC NOCMAT, João Pessoa, Paraíba, 2003. 
MOREIRA, L.E.; RIPPER, J.L.M.; CALIMAN, F. Estruturas autotensionadas com bambus e cabos aplicadas a coberturas aéreas, Gestão Universitária, 2010 laccessed on 30 January 2017).

MYERS, T. Trilhos anatômicos: meridianos miofasciais para terapeutas manuais e do movimento. Barueri, SP: Manole, 2003.

PIRET, S.; BÉZIERS, Marie-Madeleine. A coordenação motora: aspecto mecânico da organização psicomotora humana. São Paulo: Summus, 1992.

RIPPER, J.L.M.; MOREIRA, L.E.; SILVA, M.F. Desenvolvimento de estruturas autotensionadas de bambu no LOTDP. Agenda Pública: Drama Social. Rio de Janeiro: FAPERJ, 1999.

RIPPER, J.L.M.; MOREIRA, L.E.; UBÉSIO, A. Cúpula Geodésica de Bambu. Proceedings of the $V$ Encontro Brasileiro em Madeiras e em Estruturas de Madeira. Belo Horizonte, EEUFMG 1995. 12p.

ROLAND, C. Frei Otto: Spannweiten: Ideen und Versuche Leichtbau. Berlin: Verlag Ullstein $\mathrm{GmBH}, 1965$.

ROSNAY, J. de. O homem simbiótico: perspectivas para o terceiro milênio. Petrópolis/ RJ: Vozes, 1997

SANTOS, A. A biomecânica da coordenação motora. São Paulo: Summus, 2002.

SARAMAGO, J. A caverna. Portugal: Editorial Caminho, 2000.

SCARR, Graham M. Biotensegrity: The Structural Basis of Life, Scotland, Handspring Publishing Limite, 2015.

SNELSON, K. Continuous tension, discontinuous compression structures. US patent 3.69.611. 16 de Fevereiro, 1965

SNELSON, K. The art of Tensegrity. International Journal of Space Structures, Vol. 27, No. 2 \& 3, 2012, pp. 70-80.

SEIXAS, M. Quiosque itinerante de bambu. Departmento de Artes \& Design. Rio de Janeiro: PUC-Rio, 2001.

SEIXAS, M.A. Inserção social de arquiteturas temporárias de bambus e lonas têxteis utilizando tecnologias não convencionais. Dissertação de mestrado, Departmento de Artes \& Design. Rio de Janeiro: PUC-Rio, 2009.

SEIXAS, M.A.; RIPPER, J.L.M.; GHAVAMI, K. Prefabricated bamboo structure and textile canvas pavilions. Journal of the International Association for Shell and Spatial Structures, Vol. 57 no 189, 2016, pp. 179-188. DOI: 10.20898/j.iass.2016.189.782

SEIXAS, M.; BINA, J.; STOFFEL, P.; RIPPER, J.L.M.; MOREIRA, L.E.; GHAVAMI, K. Active bending and tensile pantographic bamboo hybrid amphitheater structure. Journal of the International Association for Shell and Spatial Structures, Vol. 58 no 193, 2017. DOI: 10.20898/j.iass.2017.193.872

SWANSON, L. R. Biotensegrity: A Unifying Theory of Biological Architecture With Applications to Osteopathic Practice, Education, and Research-A Review and Analysis The Journal of the American Osteopathic Association, January 2013, Vol. 113, 34-52.

VICTOR, G. R. Design para a saúde. Tese de Doutorado em Artes \& Design - Pontifícia Universidade Católica do Rio de Janeiro, Rio de Janeiro, 2008. http://www2.dbd. puc-rio.br/pergamum/biblioteca/php/mostrateses.php?open=1\&arqtese=0410917_08_ Indice.html 